\title{
Skipped spawning in Northeast Arctic haddock Melanogrammus aeglefinus
}

\author{
J. E. Skjæraasen ${ }^{1, *}$, K. Korsbrekke ${ }^{2}$, T. Nilsen ${ }^{3}$, M. Fonn ${ }^{2}$, O. S. Kjesbu ${ }^{1,4}$, \\ G. E. Dingsør ${ }^{1}$, R. D. M. Nash ${ }^{1}$ \\ ${ }^{1}$ Institute of Marine Research and Hjort Centre for Marine Ecosystem Dynamics, 5817 Bergen, Norway \\ ${ }^{2}$ Institute of Marine Research, 5817 Bergen, Norway \\ ${ }^{3}$ Department of Mathematics, University of Bergen, 5020 Bergen, Norway \\ ${ }^{4}$ Centre for Ecological and Evolutionary Synthesis, Department of Biosciences, University of Oslo, 0316 Oslo, Norway
}

\begin{abstract}
Large interannual fluctuations in the numbers of offspring joining a teleost population are common, yet factors affecting offspring production, a key driver of fish population size and demography, are often poorly understood. For some iteroparous teleosts, spawning omission ('skipping') following sexual maturation may occur, but this is typically difficult to verify. Through the detection of post-ovulatory follicles, i.e. evidence of past spawning activity, in gonads of females not spawning in the current year, we demonstrate skipping in Northeast Arctic (NEA) haddock Melanogrammus aeglefinus. Based on samples obtained just prior to the main spawning season in the Barents Sea from February to April in 2009 to 2012, the estimated population frequency of skippers ranged from 23 (2009) to $64 \%$ (2011) for females $\geq 35 \mathrm{~cm}$ in total length found in this area at this time. Skipping was associated with limited energy reserves and persisted with age, although it appeared to be most common in $5 \mathrm{yr}$ old females. This suggests that skipping is linked to a combination of feeding condition and demography of the fish population. While previously virtually undocumented in this species, this phenomenon appears to be an integral life history feature for NEA haddock and may have a major impact on the annual realised egg production in this population. Finally, given the similarity between the results reported here and those recently published for NEA cod, we postulate that skipping may be a common occurrence in gadoids undertaking long, energetically demanding spawning migrations.
\end{abstract}

KEY WORDS: Gadoids - Population regulation - Skipped spawning · Energy reserves · Animal migrations

\section{INTRODUCTION}

A thorough understanding of factors affecting offspring production is key to understanding fluctuations in fish population dynamics and demography. The energy allocated towards reproduction will be traded off against allocation towards growth and maintenance, and allocation patterns may differ markedly between species and populations with different life histories (Zera \& Harshman 2001, Ricklefs \& Wikelski 2002, McBride et al. 2015). In some teleosts, large fluctuations in population size over short

*Corresponding author: jones@imr.no time scales occur, suggesting that early life stage production may also vary substantially. Assumed relationships between spawning stock biomass (SSB) and recruitment, with the latter in fisheries terms often referring to the numbers of individuals that reach an age or size when they start to become harvested, commonly only partly explain such variation (Ulltang 1996, Mehault et al. 2010, Lowerre-Barbieri et al. 2011). This shows that unidentified causes, other than variations in $\mathrm{SSB}$, contribute to the variations in recruitment. One such factor may be skipped spawning, the failure of iteroparous teleosts to participate in

(C) The authors 2015. Open Access under Creative Commons by Attribution Licence. Use, distribution and reproduction are unrestricted. Authors and original publication must be credited. 
every spawning opportunity following initial sexual maturation (Rideout et al. 2005, Rideout \& Tomkiewicz 2011). If this is common, methodologies that assume all sexually mature individuals reproduce in every spawning season could lead to serious overestimation of SSB. Alternative models, however, require accurate classification of skipped spawners relative to maturing, spawning and especially spent individuals. Although skipped spawning is theoretically postulated to reduce annual production of early life stages in some species (Jørgensen et al. 2006), unequivocally documenting the phenomenon in the wild is difficult. This is due to the seasonal cyclic nature of gonad size (Tyler \& Sumpter 1996), the fact that teleosts become sexually mature at different sizes and ages (Heino et al. 2002) and the technical difficulty in identifying skippers, using either traditional macroscopic or microscopic staging systems (Witthames et al. 2010). Even so, skipped spawning has been reported in a variety of species with contrasting life styles (Rideout et al. 2005, Rideout \& Tomkiewicz 2011), with new examples of this phenomenon continuously being documented (Morbey \& Shuter 2013, Nahrgang et al. 2014, Sitar et al. 2014).

For gadoids, skipped spawning studies have mainly been undertaken on Atlantic cod Gadus morhua (Rideout et al. 2000, 2006, Skjæraasen et al. 2009), and this phenomenon has largely been ignored in the other species of this group. For example, to our knowledge, the only putative skipped spawning report in Atlantic haddock Melanogrammus aeglefinus is a small-scale laboratory study (Hislop et al. 1978). The presence of post-ovulatory follicles (POFs) provides unequivocal evidence of past spawning activity (Witthames et al. 2010). For most teleosts, these follicles have a very short duration and may disappear just $24 \mathrm{~h}$ after spawning (Mylonas et al. 2007). Recent studies have revealed that POFs may last for up 2 yr post-spawning in some North Atlantic gadoids (Witthames et al. 2010), providing a unique unequivocal marker of past spawning in these species. These highly different degeneration rates are thought to be positively dependent on in situ temperatures (Witthames et al. 2010). POFs were recently used to demonstrate frequent skipped spawning in the Northeast Arctic (NEA) cod (Skjæraasen et al. 2012).

Here, we evaluate the occurrence of skipped spawning in the relatively large population of NEA haddock. The main feeding areas of this population are in the Barents Sea, whereas maturing adults migrate to spawning areas in the Norwegian Sea, where spawning occurs from mid-March to early
June, before returning to the Barents Sea in late summer. Early life history stages are then carried into the Barents Sea nursery areas from the spawning grounds by the prevailing currents (Bergstad et al. 1987). To evaluate whether skipped spawning is occurring in this culturally and commercially important gadoid, large numbers (>1350) of female haddock were sampled in 4 consecutive field seasons from 2009 to 2012 and subsequently examined, in the laboratory, for past and present spawning history.

\section{METHODS}

\section{Field samples}

Female NEA haddock $\geq 35 \mathrm{~cm}(\geq 30 \mathrm{~cm}$ in 2012) were collected during the annual Barents Sea winter surveys conducted by the Institute of Marine Research (IMR) in February and March 2009 ( $n=109)$, 2010 ( $\mathrm{n}=525), 2011(\mathrm{n}=411)$ and $2012(\mathrm{n}=341)$, in total 1386 specimens (Fig. 1). As previously mentioned, NEA haddock spawning predominantly occurs in the Norwegian Sea from mid-March to early June (Bergstad et al. 1987). The duration of vitellogenesis in this species is probably 6 mo or even longer (Kjesbu et al. 2010, Skjæraasen et al. 2013). Therefore, the timing of this survey is such that even when accounting for individual variability in the timing of spawning, any female not showing vitellogenic oocytes at the time of the survey would not be ready for spawning in the survey year. The standard protocol for a catch is for all sampled females to be measured for total length (hereafter abbreviated as 'length'), truncated to the nearest centimeter below, i.e. a female of $40.7 \mathrm{~cm}$ will be given the length $40 \mathrm{~cm}$, and whole body, liver and gonad weight (truncated to the nearest gram below). Even so, for one reason or another, either gonad and/or liver weight were missing from a random selection of females; thus, 1361 females were associated with a complete set of data. Samples of the gonads $(n=1386)$ were stored in neutral buffered formaldehyde (3.6\%) (Bancroft \& Stevens 1996) for later laboratory analyses at IMR, and otoliths were collected for age determinations.

\section{Laboratory analyses}

The gonad samples were first sorted macroscopically into those that were developing $(\mathrm{D} ; \mathrm{n}=534)$ and those that were not developing (ND; $\mathrm{n}=852$ ) oocytes. 
All samples designated D were subjected to digital image analyses (Thorsen \& Kjesbu 2001) confirming the presence of vitellogenic oocytes in each of the females. Then, 829 of the ND samples and 182 of the D samples were examined histologically, using standard protocols for resin embedding (Technovit $\left.7100^{\circledR}\right)$ for classification of oocytes into previtellogenic, cortical alveoli or yolk granule stages (Tyler \& Sumpter 1996). All histological sections were also screened for the presence of POFs, i.e. unequivocal evidence of past spawning activity (Saborido-Rey \& Junquera 1998, Witthames et al. 2009). The presence/absence of POFs in ND samples allowed us to further subdivide this group into immatures (no POFs) and skippers (POFs present), given that samples were obtained close to the expected onset of the NEA haddock spawning season and that any wouldbe spawning females therefore should possess welldeveloped vitellogenic oocytes at this time (Kjesbu et al. 2010).

\section{Data analyses}

\section{Gonad size and development}

The intention of the analyses was to examine if gonad size could be linked to (1) the probability of being a skipped spawner or sexually immature, considering only ND females, given that such information could theoretically be extrapolated and used to identify skippers in datasets where no POF information is available, and (2) the probability of developing or not developing oocytes, considering all females. For both analyses, we used relative gonad size, i.e. gonadosomatic index $($ GSI $)=$ Gonad weight $\times($ Total weight - Gonad weight - Liver weight $)^{-1} \times 100$ as our dependent variable.

For (1), we employed the following initial model:

$$
\begin{gathered}
\text { GSI }=\text { Length } \times \text { Spawning history }+ \\
\text { Capture day } \times \text { Spawning history }
\end{gathered}
$$
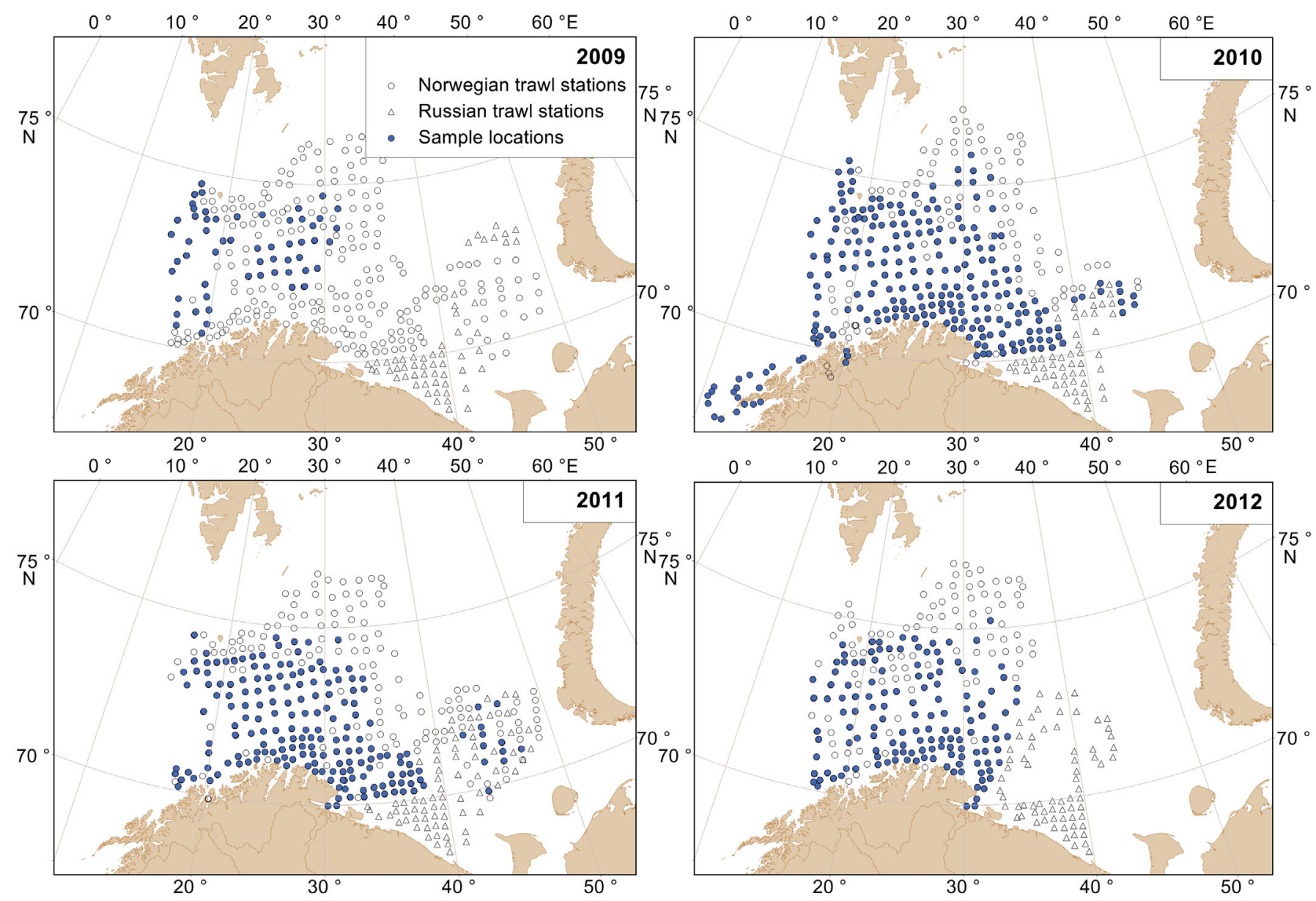

Fig. 1. All sampling stations covered annually from 2009 to 2012 in the combined Norwegian (circles) and Russian (triangles) winter survey in the Barents Sea undertaken during February and March. Blue circles represent stations where samples were obtained for laboratory analyses 
Spawning history, i.e. immature or skipping females as determined by the presence/absence of POFs in the histological analyses, was treated as a categorical variable, and length and capture day were treated as continuous variables. The variable length was centred at its mean to allow easier group comparisons. For capture day, we coded the earliest sampling day in our data, i.e. January 25, as 0 , and subsequent sampling days were given a number equal to the number of days past this day, e.g. March 1 was given the number 35. The model was simplified sequentially by the removal of non-significant terms, using the Bayesian information criterion (BIC) terms to arrive at the most parsimonious model (Venables \& Ripley 1999). For (2), we first manually identified a threshold value below which the majority $(>95 \%)$ of the females were not developing oocytes. We then employed discriminate analyses to see if this indicated a similar threshold. By log-transforming the data, the variation was approximately equal among the ND and D females, justifying the use of Fisher's linear discriminant function for the logarithms of the data.

\section{Energy reserves, developmental status and spawning history}

To examine if there were differences in energy reserves, i.e. liver size, between D and ND females at the individual level, we employed the following general initial model:

Energy proxy $=$ Length $\times$ Maturity status $\times$ Year

We tested 2 different proxies of energy reserves as dependent variables: (1) absolute liver size and (2) relative liver size [hepatosomatic index $(\mathrm{HSI})=100 \times$ liver weight $\times$ (Total weight - Gonad weight - Liver weight $)^{-1}$ ], given that liver size is a good indicator of lipid reserves (Lambert \& Dutil 1997, Marshall et al. 1999, Skjæraasen et al. 2010). The current developmental status, i.e. D or ND females, and year were treated as categorical variables, and length was treated as a continuous variable. Since we allowed different slopes depending on the values of maturity status and year in the initial models, it was convenient to centre length at its mean, i.e. $47.4 \mathrm{~cm}$. This gave an easier comparison of the main effects across the groups. Our initial models contained all possible interactions, and these models were then simplified as described previously. For the test involving absolute liver size as the dependent variable, the dependent variable and length were $\log _{\mathrm{e}}$-transformed before applying the model.
To examine quantitative differences between skipping or sexually immature fish at the individual level, i.e. ND fish only, and their seasonal occurrence, we modelled spawning history, i.e. skipper or immature corresponding to the presence/absence of POFs, by logistic regression, with spawning history as a binomial response variable, using the following initial model for the linear predictor:

$$
\text { Spawning history }=\text { Length } \times \text { HSI } \times \text { Year }
$$

The model was again simplified sequentially by removing non-significant terms, using the BIC, to arrive at the most parsimonious model (Venables \& Ripley 1999), and length was again centred at its mean, i.e. $47.4 \mathrm{~cm}$.

\section{Population-level analyses}

The gadoid populations in the Barents Sea are surveyed in February to April through a combined effort of Norwegian and Russian research vessels. This survey includes a dedicated extensive bottom trawl sampling programme with more than 100 geographical locations, i.e. trawl stations, sampled annually (Fig. 1). At each trawl station, the biological sub-sampling is stratified into $5 \mathrm{~cm}$ length groups, with 1 sampled specimen per length group. Individual information, i.e. length, weight, age (from otoliths), sex, liver weight, gonad weight and maturity stage, is collected from these specimens, and this information was subsequently used to characterize the estimated population present at this time. To upscale this biometric information from the individual to the population level, statistical weighting factors, $W_{j}$, were assigned to each single fish $(j)$ observation. These weighting factors were calculated as the inverse of the sampling probability (inclusion probability) (Horvitz \& Thompson 1952). Hence, the probability of sampling a given single fish was set equal to the probability of the trawl sample itself, swept area relative to total survey area, multiplied by the probability of being sub-sampled from the catch in question (see the Supplement at www.int-res.com/articles/suppl/m526p143_supp.pdf for details of the method). This weighting principle was used in all analyses below.

Although the sampling resulted in an extensive spatial coverage, we unfortunately did not obtain samples for laboratory examinations allowing us to determine developmental stage from all survey stations (Fig. 1). However, as part of the survey sampling routine, all individually sampled females were given a code based on macroscopic examination of 
gonad size and appearance to divide fish into developing, i.e. $\mathrm{D}$, females (code $2=$ maturing and code 3 = spawning) and non-developing, i.e. ND, females (code $1=$ immatures, code $4=$ resting/spent and code $5=$ uncertain). This coding closely matched ( $>95 \%$ of the fish and $>95 \%$ similarity in the calculated abundance index, see description of the latter in Eqs. (4) to (6) and related text) the results from our laboratory classification in the instances where both data types were available for both $\mathrm{D}$ and ND females in the years 2010 to 2012. In 2009, this was not the case, as the abundance index for D fish was $33 \%$ lower if using the macroscopic coding compared to the result obtained if using the laboratory classification. For the years 2010 to 2012, we therefore used the macroscopic coding for the entire winter survey, i.e. both the Norwegian and Russian samples, to divide fish into D females and ND females and subsequently used this information to estimate size-dependent proportions of females developing oocytes. Given the disparity between our laboratory classification and the macroscopic coding in 2009, we principally used the sampling stations from which we had laboratory samples to estimate size-dependent proportions of females developing oocytes in this year. However, we did boost our sample size in 2009 by also including sampling stations where we had information on gonad weight, given that this also can be used to distinguish D and ND females (see 'Results').

In all years, we first calculated (1) the weighted proportion of developing females among the total number of females $\left(P_{\mathrm{dev}}\right)$ and (2) the proportion of skipping females among ND females $\left(P_{\text {skip }}\right)$ as a function of size, i.e. splitting the samples into the following $5 \mathrm{~cm}$ length groups: 30 to 34 (2012 only), 35-39, $40-44,45-49,50-54,55-59,60-64,65-69,70-74$ and $75-79 \mathrm{~cm}$. The estimate of $P_{\text {skip }}$ was always based solely on samples from the trawl stations which had been examined in the laboratory. We then estimated the uncertainties in our size-dependent estimates by creating 500 replicated datasets, using a standard bootstrap procedure (Davidson \& Hinkley 1997). For some fish, only information on length and not sex was available ( 2 to $8 \%$ in our study years). The weighting factors for these fish were assigned to length groups according to the proportion of females in each length group, calculated from all samples where sex had been determined.

Similarly, we also calculated (1) $P_{\text {dev }}$ and (2) $P_{\text {skip }}$ as a function of age, i.e. splitting the samples into the following age groups: $3,4,5,6,7,8$ and $9+(\geq 9 \mathrm{yr})$. For ages 3 (especially), 4 and sometimes 5, samples included fish below the earlier defined minimum tar- get length, i.e. $<35 \mathrm{~cm}$ in 2009 to 2011 and $<30 \mathrm{~cm}$ in 2012, where we had no access to laboratory information on gonad status. We therefore made the assumption that all fish below our target length range within a given age were sexually immature. There were also some fish for which only length information and no sex or age information was available. The weighting factors for these fish were assigned to age groups according to the proportion of females in each length group for every given age, calculated from all samples where sex and age had been determined.

We then calculated the total annual abundance index, i.e. the number of fish, of developing (Eq. 4), skipping (Eq. 5) and immature (Eq. 6) females, summed up over the length groups or age groups (i) described above, as:

$$
\begin{gathered}
\text { Developing }_{i}=\sum_{j=1}^{n} w_{j} \times y_{j}(\operatorname{Dev}, i) \\
\text { Skipping }_{i}=\sum_{j=1}^{n} w_{j} \times y_{j}(\text { Skip }, i) \\
\text { Immature }_{i}=\sum_{j=1}^{n} w_{j} \times y_{j}(\text { Imm }, i)
\end{gathered}
$$

where $w_{j}$ is the weighting factor (see also methods in the Supplement)i $y_{j}(D e v, i)=1$ if fish $j$ is developing and length/age $=i$ and 0 otherwise.

A highly conservative measure of the uncertainty in our stock estimates utilised the length-group specific end points of the $90 \%$ confidence intervals from the bootstrap analyses, described above, to calculate the resulting uncertainty range in immatures, skippers and spawners at the stock/population level.

As stated in the 'Introduction', NEA haddock undertake a long-distance spawning migration out of the Barents Sea to the main spawning areas in the northern Norwegian Sea, with the main migration believed to commence in December and spawning females returning in June to July (Bergstad et al. 1987). Unfortunately, the spawning areas are not covered by any research cruises. Our annual population index, based on samples from the Barents Sea in February to April, is thus most likely biased in that the numbers of spawning females are underestimated. To evaluate the extent of this latter bias, a tentative correction was therefore also applied; there is a difference between our numerical estimates from the winter survey alone and the total stock size as reported by ICES (Fig. 2). The latter number builds on several additional Norwegian and Russian surveys which predominantly occur in the Barents Sea at different times of the year (ICES 2012). We simplistically assumed that (1) this numerical difference was caused entirely by developing haddock of an equal 

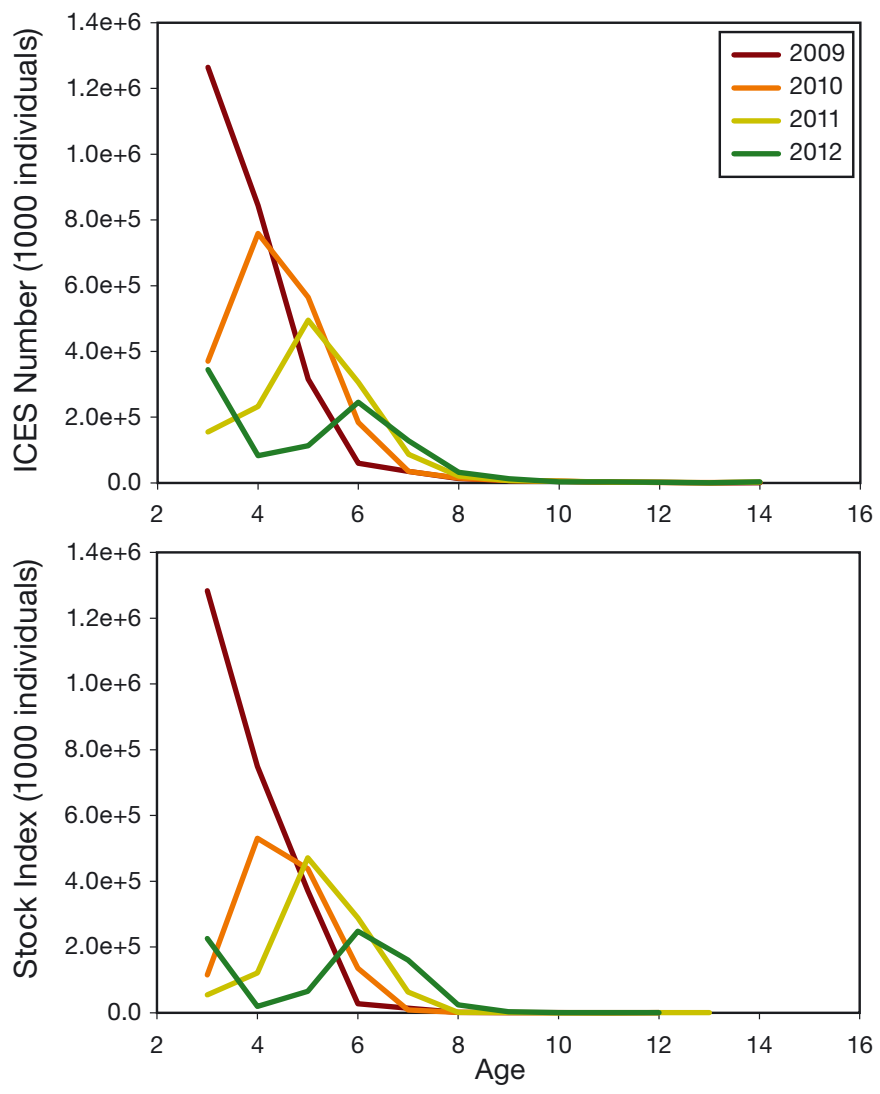

Fig. 2. Official ICES statistics (upper panel) showing the number of fish at age 3 to 16 yr from 2009 to 2011 and our calculated value (lower panel) from the annual indices based on the winter survey only. Both sexes combined

Table 1. Percentage of Northeast Arctic haddock in different ovarian developmental stages in different seasons determined by histology $(\mathrm{n}=1011)$. The most advanced (leading) oocyte stage was used as the classification criterion. Potential skippers were divided into those with previtellogenic oocytes (PVO, $<250 \mu \mathrm{m}$ ) and those with early cortical alveoli oocytes (E-CAO, $250 \mu \mathrm{m}<\mathrm{LC} 20<300 \mu \mathrm{m})$. The latter were not detectable by automated image analyses of developing oocytes (Thorsen \& Kjesbu 2001), but were staged as CAO in the histology. LC20 is the average diameter of the 20 largest oocytes measured (Thorsen \& Kjesbu 2001). The occurrence of post-ovulatory follicles denoted that an individual was sexually mature, although presently with no clear sign of oocytes in true vitellogenesis, and not an immature (see 'Methods: Laboratory analyses'). All fish developing vitellogenic oocytes detectable by automated image analyses possessed yolk granule oocytes (YGO)

\begin{tabular}{|cccccccc|}
\hline \multirow{2}{*}{ Year } & \multicolumn{3}{c}{ Potential skippers } & \multicolumn{3}{c|}{ Developing } \\
& PVO & E-CAO & YGO & n & YGO & n \\
\hline 2009 & 98.6 & 0 & 1.4 & 71 & 100 & 24 \\
2010 & 97.5 & 2.5 & 0 & 314 & 100 & 85 \\
2011 & 98.8 & 0.8 & 0.8 & 262 & 100 & 73 \\
2012 & 95.6 & 2.7 & 1.6 & 182 & - & - \\
\hline
\end{tabular}

sex ratio residing at spawning grounds outside the Barents Sea during the winter survey and (2) any fish caught during the winter survey below our yearly target range were sexually immature. We then calculated the spawner-to-skipper ratio (1) based solely on our Barents Sea winter survey index numbers and (2) using the correction described above to see if the latter approach reduced the numbers of skippers in the population to biological insignificance.

\section{RESULTS}

\section{Gonad size as an indicator of vitellogenesis}

All D females reached the yolk granule stage (Table 1), whereas ND females predominantly possessed only previtellogenic oocytes (Table 1). Gonad size could not be used to distinguish between skipping and immature fish; early in the sampling period, i.e. February, skipping females tended to have larger gonads than immatures $(t=3.36, \mathrm{df}=803, \mathrm{p}<0.001)$, but there was also an interaction between sampling day and spawning history $(t=-3.48$, df $=803$, p < 0.001), with immatures tending to have larger gonads towards the end of the sampling period (Table 2). Although these variables were significant, the amount of variation explained by our final model was very low $(1.2 \%)$. In contrast, gonad size was an accurate indicator of ongoing vitellogenesis, with an approximate GSI value of 1.7 separating $\mathrm{D}$ and ND females. Below this threshold value, only $0.7 \%$ of the females possessed vitellogenic oocytes $(n=809)$, whereas the majority of females with GSI $>1.7$ possessed vitellogenic oocytes (94.4\%; $\mathrm{n}=552$, Fig. 3A). The subsequent discriminant analyses gave similar threshold values separating D and ND females, with values of $1.91,1.91,1.78,2.00$ and 1.87 for 2009, 2010, 2011, 2012 and all years pooled, respectively. In the analyses of the proportion of D and ND females at the population level in 2009 (see 'Results: Skipped spawning scaled to the population level'), we therefore designated fish not examined in the laboratory, but with known gonad weight, as ND females if GSI $<1.7$ and as D females if GSI $>1.7$.

\section{Gonad development, energy reserves and traits separating skipping and immature females}

Liver size was tightly linked to gonad development, with ND females exhibiting significantly smaller livers $(p<0.00001$, Fig. 3B, Table 2$)$. This 
Table 2. Final models comparing gonad size (gonadosomatic index, GSI) between immatures and skippers, i.e. spawning history; energy proxies comparing females developing and not developing oocytes (developmental status), i.e. liver weight and hepatosomatic index $\left(\right.$ HSI $=100 \times$ Liver weight $\left.\times(\text { Total weight }- \text { Gonad weight }- \text { Liver weight })^{-1}\right)$; and logistic regression examining traits associated with spawning history for females not developing oocytes. Models were run with treatment contrast. For the model on gonad size intercept and capture day, values depict estimated values for immatures; for the liver size models, intercept and length (slope) values depict estimated values for 2010 for non-developing females. Intercept and slope values for 2009, 2011 and 2012 and developing females/skippers can be calculated by adding/subtracting the given values for these variables, i.e. the year in question or spawning history/developmental status. For the model on energy reserves and the logistic regression, $\log _{\mathrm{e}}$ length and length are centred at the mean. For the logistic regression, positive values are associated with traits/factors increasing the likelihood of a fish being a skipped spawner and not an immature. Value = the model estimate for the variable in question, $t / z=$ the value of the test for the variable in question (these are $t$-values, except for the test on spawning history, which is a $z$-value, given that this was a logistic regression with a binomial response variable)

\begin{tabular}{|c|c|c|c|c|c|c|}
\hline Proxy & Variable & Value & $\mathrm{SE}$ & $\mathrm{df}$ & $t / z$ & $\mathrm{p}$ \\
\hline \multirow{4}{*}{$\begin{array}{l}\text { Gonad size (GSI) } \\
\text { (adjusted } \mathrm{R}^{2}=0.012 \text { ) }\end{array}$} & Intercept & 0.44 & 0.12 & 803 & 3.65 & $<0.001$ \\
\hline & Capture day & 0.015 & 0.0048 & 803 & 3.08 & $<0.01$ \\
\hline & Spawning history & 0.50 & 0.15 & 803 & 3.36 & $<0.001$ \\
\hline & Capture day:Spawning history & -0.02 & 0.0058 & 803 & -3.48 & $<0.001$ \\
\hline \multirow{7}{*}{$\begin{array}{l}\log _{\mathrm{e}} \text { liver weight } \\
\text { (adjusted R }{ }^{2}=0.78 \text { ) }\end{array}$} & Intercept & 3.54 & 0.04 & 1344 & 96.1 & $<0.0001$ \\
\hline & Centred $\log _{e}$ length & 3.78 & 0.08 & 1344 & 46.4 & $<0.0001$ \\
\hline & 2009 & 0.01 & 0.04 & 1344 & -0.28 & 0.78 \\
\hline & 2011 & -0.13 & 0.04 & 1344 & -3.13 & $<0.01$ \\
\hline & 2012 & -0.03 & 0.04 & 1344 & -0.66 & 0.51 \\
\hline & Developmental status & 0.44 & 0.025 & 1344 & 17.9 & $<0.0001$ \\
\hline & Centred $\log _{\mathrm{e}}$ length:Developmental status & -0.54 & 0.15 & 1344 & -3.54 & $<0.001$ \\
\hline \multirow{3}{*}{$\begin{array}{l}\text { HSI } \\
\text { (adjusted } R^{2}=0.36 \text { ) }\end{array}$} & Intercept & 3.72 & 0.053 & 1356 & 70.8 & $<0.0001$ \\
\hline & Centred length & 0.047 & 0.0056 & 1356 & 8.39 & $<0.0001$ \\
\hline & Developmental status & 1.80 & 0.090 & 1356 & 20.1 & $<0.0001$ \\
\hline \multirow{2}{*}{ Spawning history } & Intercept & 1.31 & 0.12 & 805 & 11.0 & $<0.0001$ \\
\hline & Centred length & 0.28 & 0.021 & 805 & 13.4 & $<0.0001$ \\
\hline
\end{tabular}

result was robust regardless of whether we used absolute liver size (Fig. 3B) or HSI as our dependent variable (Table 2). We also found significant effects of sampling year and interactive effects between length and developmental status in the former model (Table 2), but year effects were of smaller magnitude than the effects of developmental status, and even when accounting for interactive effects, liver weight and HSI were consistently larger for D females across our length sampling range (Table 2). Considering only the ND individual samples, the likelihood of a female being a skipped spawner and not an immature increased, as expected, with female length $(\mathrm{p}<$ 0.00001, Table 2).

\section{Skipped spawning scaled to the population level}

The proportion of $\mathrm{D}$ females generally increased with size up to approximately 50 to $60 \mathrm{~cm}$ but then levelled off and in most cases did not reach $100 \%$ in any length category (Fig. 4A). The bootstrapped confidence intervals indicated considerable uncertainty in the estimated proportions, especially among the larger size categories (Fig. 4A). Considering only ND females, the likelihood of a fish skipping spawning appeared to be strongly positively associated with fish length in all years (Fig. 4B), matching the results of the individual-based analyses. Once again, the bootstrapped confidence intervals indicated considerable uncertainty in these estimates (Fig. 4B, Table 3). In terms of age, the results showed similar trends. Very few D females were found among the 3 and 4 yr olds, with generally increasing proportions of $\mathrm{D}$ females among the older age groups. There was a tendency for lower proportions of D females at age in 2010 and 2011, and again the proportion of females developing oocytes generally did not reach $100 \%$ for any age category (Fig. 4C). The proportion of skippers among the ND females was generally low among the 3 and 4 yr olds, but for fish 5 yr and older, it was generally very high and usually close to $100 \%$ (Fig. 4D).

The estimated annual proportion of female haddock found in the Barents Sea in February to April that were skipping spawning varied greatly at the stock level (Fig. 5A-D). In our sample size ranges, the estimated values ranged from $23 \%$ skipping 

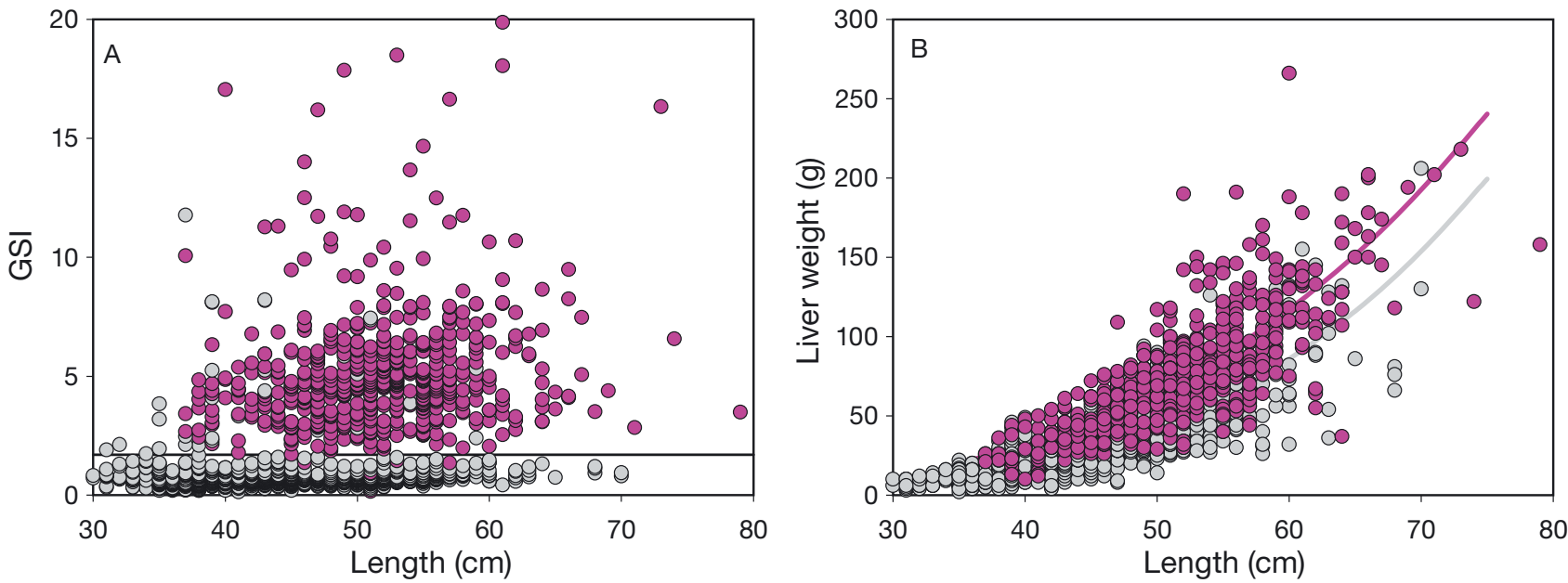

Fig. 3. (A) Relative gonad size, i.e. gonadosomatic index (GSI $=100 \times$ Gonad weight $\times$ (Total weight - Gonad weight - Liver weight $)^{-1}$ ) versus total length $(\mathrm{cm})$. Pink circles $=$ females developing oocytes, grey circles $=$ females not developing oocytes. Horizontal line $=$ GSI value of $1.7 \%$. (B) Length versus liver weight; fitted lines are the resulting regression lines obtained from a regression on $\log _{\mathrm{e}}$-transformed individual data on length and liver size for developing fish (purple line) and non-developing fish (grey line) in 2010, added for illustrative purposes
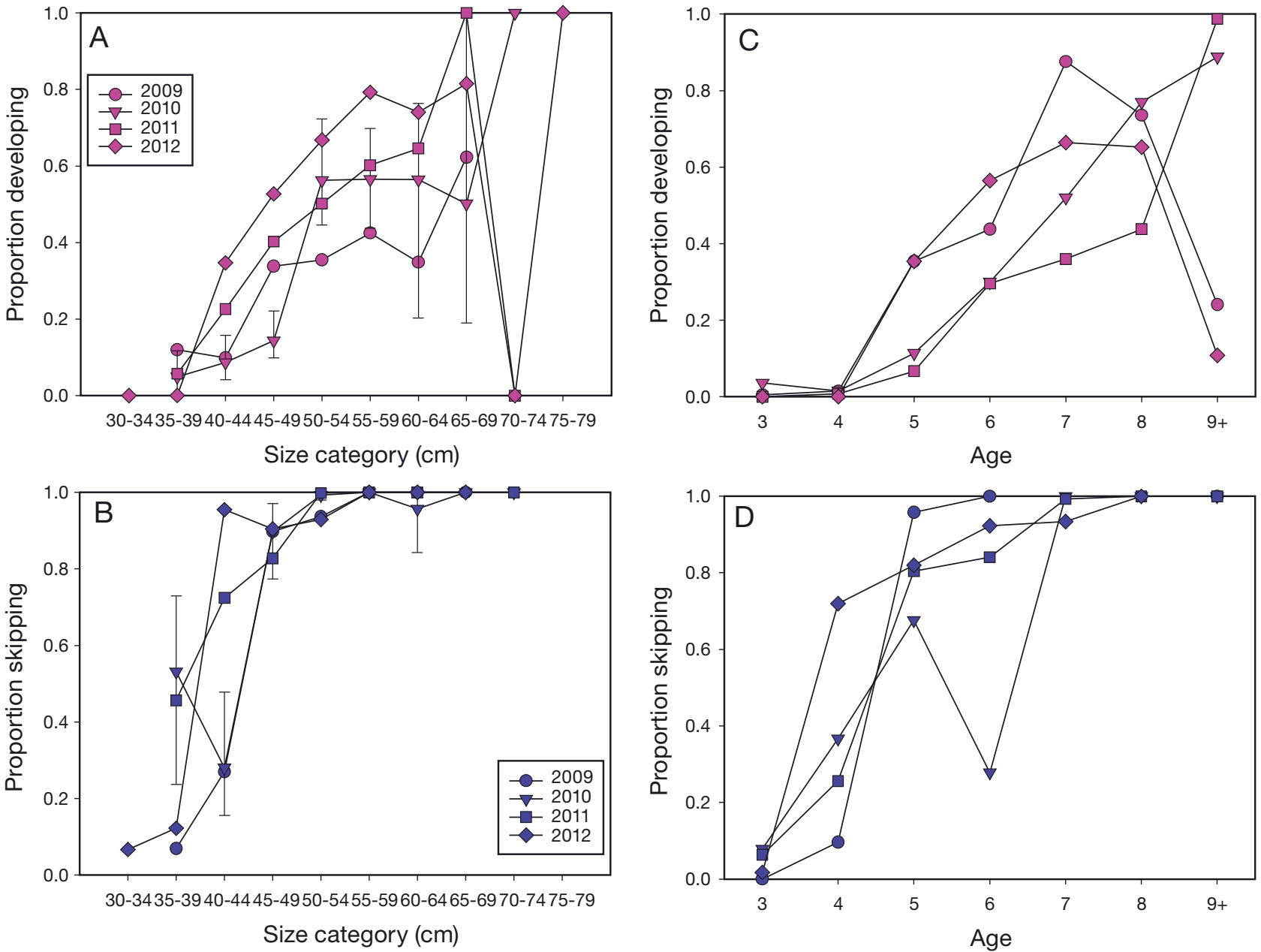

Fig. 4. Population-level calculations of the proportions of $(A, C)$ females developing oocytes and (B,D) skipped spawners among females not developing oocytes in 2009 to 2012 for each $5 \mathrm{~cm}$ length category $(\mathrm{A}, \mathrm{B})$ and age $(\mathrm{C}, \mathrm{D})$ ). Error bars $(\mathrm{A}, \mathrm{B}) \mathrm{rep}-$ resent $90 \%$ confidence interval as calculated from the bootstrap analyses. These are only shown for the year 2010 in both panels but were of approximately similar magnitude in all sampling years. Note that for length categories $>69 \mathrm{~cm}$ and age $9+$, few 
Table 3. Estimated population-level percentages of immature, skipping and developing female Northeast Arctic haddock in 2009 to 2012. The numbers are based on samples from the Barents Sea only in February to April. Ranges given in brackets represent conservative uncertainty intervals for the calculated index, obtained as a weighted mean of either all of the lower ends or all of the upper ends of the bootstrapped $90 \%$ confidence intervals for each $5 \mathrm{~cm}$ length group as presented for 2010 in Fig. 4A,B

\begin{tabular}{|lllll|}
\hline Year & $\begin{array}{c}\text { Size } \\
\text { category }\end{array}$ & Immature & Skipping & Developing \\
\hline 2009 & $\geq 35 \mathrm{~cm}$ & $60(40-79)$ & $23(8-41)$ & $17(6-33)$ \\
2010 & $\geq 35 \mathrm{~cm}$ & $44(26-65)$ & $45(25-64)$ & $11(6-18)$ \\
2011 & $\geq 35 \mathrm{~cm}$ & $22(7-40)$ & $64(43-84)$ & $14(8-21)$ \\
2012 & $\geq 30 \mathrm{~cm}$ & $34(29-41)$ & $28(17-44)$ & $38(27-46)$ \\
\hline
\end{tabular}

spawning in 2009 to $64 \%$ skipping spawning in 2011 (Table 3). Looking at the number of skippers according to age, few skippers were found among the 3 (especially) and $4 \mathrm{yr}$ olds, whereas they dominated among the $5 \mathrm{yr}$ olds both in absolute and relative numbers (Fig. 5E-H). Skippers were also quite prevalent among females > $5 \mathrm{yr}$, but these older age classes generally were dominated by $\mathrm{D}$ females (Fig. 5E-H). The spawner-to-skipper ratio in the population was $0.75,0.24,0.22$ and 1.35 for 2009, 2010, 2011 and 2012, respectively, when calculated based on our Barents Sea winter survey indices alone and 1.29, 1.83, 0.71 and 2.49 for 2009, 2010, 2011 and 2012, respectively, when tentatively adjusting for spawning females outside the Barents Sea at the time of the winter survey (Fig. 6).
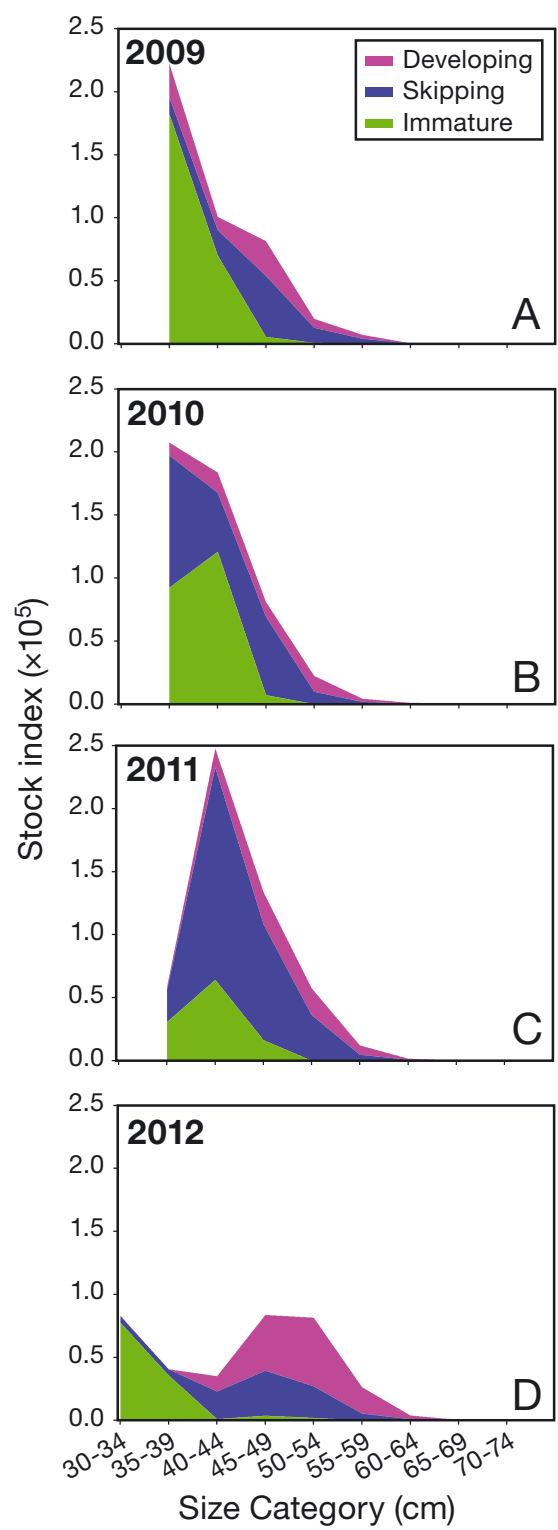
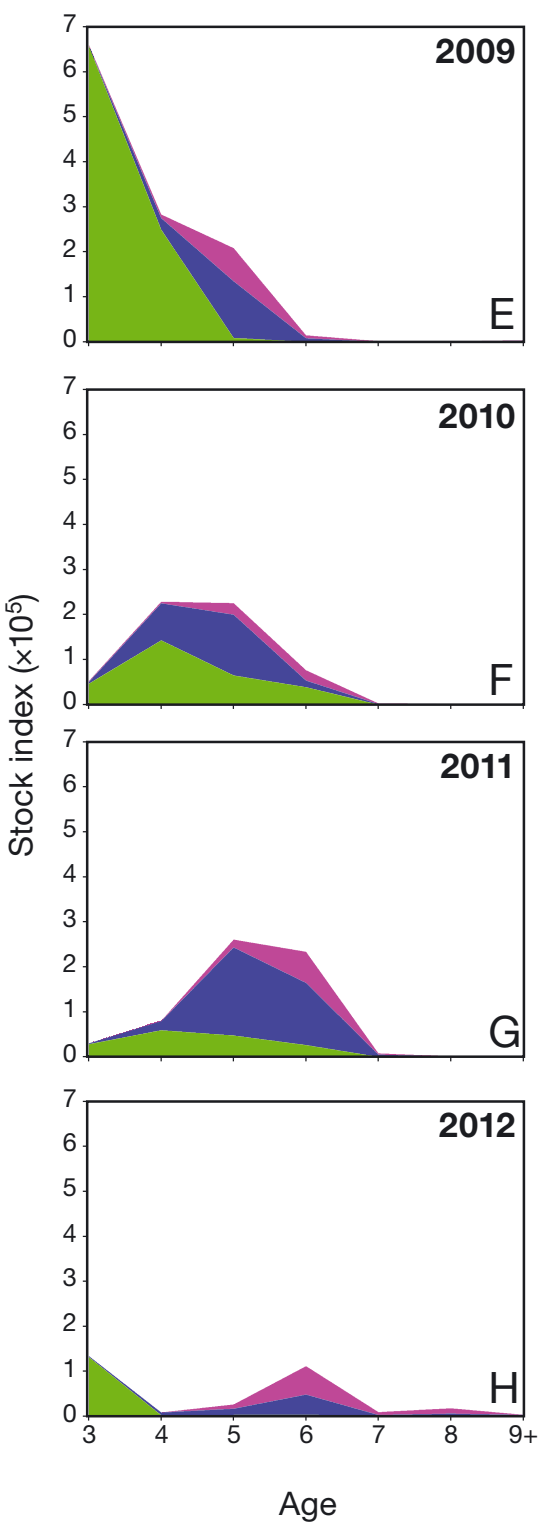

\section{DISCUSSION}

Our study unequivocally demonstrates frequent skipped spawning in NEA haddock. Compared to a theoretical population where all sexually mature individuals reproduce annually, skipping thus may profoundly reduce annual egg production in this population. The results of the present study match those recently reported for cod, the only other NEA gadoid examined for skipped spawning (Skjæraasen et al. 2012). Skipped spawning may be a common feature in many gadoids, but we suspect that this phenomenon may be particularly prevalent in populations where reproduction is associated with a lengthy migration between feeding and spawning areas.

Fig. 5. Calculated stock indices for 2009 to 2012 showing the annual number of immature, skipping and spawning females as a function of $(\mathrm{A}, \mathrm{B}, \mathrm{C}, \mathrm{D})$ size and $(\mathrm{E}, \mathrm{F}, \mathrm{G}, \mathrm{H})$ age. Based on samples from the winter survey in the Barents Sea only. Note that large numbers of fish below our sampling range ( 35 or $30 \mathrm{~cm}$ ) were found among the 3 and, to some extent, the $4 \mathrm{yr}$ olds, and these have been included in plots $\mathrm{E}, \mathrm{F}, \mathrm{G}, \mathrm{H}$. There is therefore a difference in the scale for the $y$-axis between $A, B, C, D$ and $E, F, G, H$ 


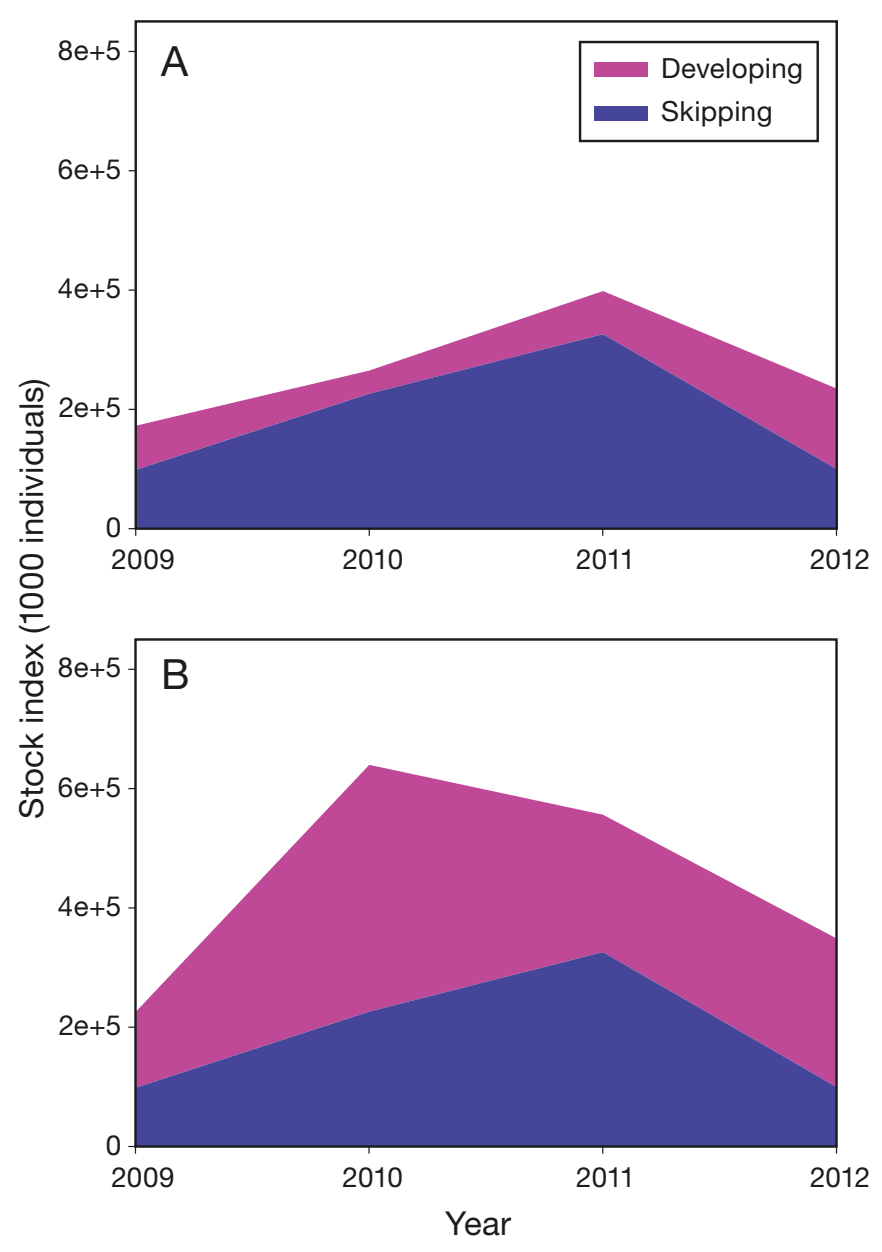

Fig. 6. Total numbers of fish developing oocytes (purple area) and skipping spawning (blue area) in 2009 to 2012, based on (A) only the winter survey and (B) adjusted through the use of official ICES numbers by assuming that all skippers are accounted for in the winter survey and that the numerical difference between the ICES numbers and the winter survey index for fish $\geq 3$ yr is caused entirely by spawning Northeast Atlantic haddock of an equal sex ratio residing outside the Barents Sea at the time of the winter survey

Intermittent reproduction has been reported in a variety of animal taxa (Bull \& Shine 1979, McNamara \& Houston 2008, Folkvord et al. 2014). There are 2 main theories, although not mutually exclusive, as to why this occurs: (1) insufficient energy reserves to support successful reproduction, including in its broadest sense not only the energy deposited in the developing oocytes (fecundity and or egg size/ quality) but also other costs associated with reproduction such as the costs of any breeding migration, brooding or costs associated with the spawning act itself (Bull \& Shine 1979); and (2) an evolutionary adaptive advantage, i.e. younger females may increase their lifetime reproductive success by investing en- ergy into length growth at a young age, allowing for higher fecundity in later years (Bull \& Shine 1979, Jørgensen et al. 2006, McNamara \& Houston 2008).

Developing females had larger energy reserves than non-developing females (Fig. 2B, Table 2), tentatively indicating that skipped spawning may be associated with limited energy reserves. Low energy reserves during spawning may increase post-spawning mortality in gadoids (Dutil \& Lambert 2000), and skipping when energy reserves get below a critical threshold during gonadal development is therefore likely adaptive (Jørgensen et al. 2006). One particular feature that may make spawning omission particularly prevalent in NEA gadoids is the cost of their long spawning migrations. NEA haddock are believed to migrate out of the Barents Sea to spawning areas along the Norwegian coast ranging from Møre in the south $\left(62^{\circ} 28^{\prime} \mathrm{N}, 6^{\circ} 11^{\prime} \mathrm{E}\right)$ to Tromsøflaket in the north $\left(72^{\circ} 20^{\prime} \mathrm{N}, 16^{\circ} 36^{\prime} \mathrm{E}\right)$. NEA haddock may thus undertake a spawning migration of more than $1000 \mathrm{~km}$ each way (Bergstad et al. 1987). Similar long-distance spawning migrations are undertaken by the other main gadoids utilising the Barents Sea as a feeding area, the NEA cod and saithe Pollachius virens (Bergstad et al. 1987). Like bird and mammal migrations (Weber et al. 1998, Hedenström 2003, 2008), the NEA gadoid spawning migrations incur considerable energetic costs (Jørgensen et al. 2008). Although migration distance may be state dependent and adjusted according to individual energy reserves (Jørgensen et al. 2008), there is nonetheless a large non-recoverable cost associated with breeding in these fishes. Similar to what has been observed in migratory snook Centropomus undecimalis (Trotter et al. 2012) and suggested to be occurring in other migratory species (Jager et al. 2008), this may make skipped spawning more prevalent in the longdistance migratory NEA gadoids compared to shortdistance migratory or non-migratory gadoid populations. NEA haddock that skipped also primarily appeared to never start endogenous vitellogenesis, i.e. reach the yolk granule stage (Table 1). Like NEA cod (Skjæraasen et al. 2012), they mainly aborted further oocyte development at an early stage (Table 1), showing a resting or early reabsorbing skipping mode (see Rideout \& Tomkiewicz 2011 for definitions). These females thus effectively aborted this year's spawning opportunity before the time of the start of the spawning migration. The complete later reabsorption of all yolk granules, i.e. 'reabsorbing vitellogenic skippers', was not observed in any of the developing females examined histologically $(n=185)$ (Skjæraasen et al. 2013). By remaining on the feed- 
ing grounds in the Barents Sea and not starting endogenous vitellogenesis, skipping NEA female gadoids thus appear to principally avoid both the costs associated with spawning migration and any catabolic costs associated with follicular atresia (Tyler \& Sumpter 1996).

While interpopulation differences in the level of skipped spawning may thus be related to migration distance, year-to-year variation within populations is likely linked to annual variation in energy reserves and/or age composition of the population. We did find a tentative link within years between energy reserves and skipped spawning in that spawning females had bigger livers (Fig. 3A), and we also found that skipped spawning was most common in $5 \mathrm{yr}$ old females in all of our sampling years (Fig. 5E-H), the latter tentatively explaining the large number of skipped spawners at the population level in 2011, when this age group was particularly prevalent. This suggests that population age composition does appear to affect the frequency of skipped spawning. Did the population also experience lower food availability in 2011? Our results are inconclusive; we did find that females had smaller livers at length in 2011 compared to the other sampling years, but relative liver size after accounting for the influence of liver and gonad size on total weight was similar among years (Table 2). Growth or size at age has also been remarkably stable for haddock in the past decades (ICES 2012).

Regarding females skipping spawning because of insufficient energy, it might be argued that females have big livers because they are spawning rather than females are spawning because they have big livers, since females developing vitellogenic oocytes will allocate energy to the liver (Tyler \& Sumpter 1996). To thoroughly evaluate this question, data on liver size around the onset of vitellogenesis is needed. Unfortunately, no such data were collected in the present study, but data for NEA cod showed that females developing oocytes did possess larger livers also around the start of vitellogenesis in the autumn (Skjæraasen et al. 2012). We suspect the same would also apply for NEA haddock. If so, this suggests that this phenomenon may function as a density-dependent response, important in population regulation for these gadoid populations. As suggested for NEA cod (Skjæraasen et al. 2012), skipped spawning may act as a compensatory mechanism in the recruitment process, by reducing egg production, similar to density-dependent mortality (Ricker 1954).

In contrast to NEA cod, skipped spawning in NEA haddock appears to persist throughout the life span
(Figs. 3A,B \& 4), whereas NEA cod females tend to spawn at older ages (Skjæraasen et al. 2012). Skipped spawning as an adaptive strategy is thought to be dependent on life expectancy, with less skipping occurring in shorter-lived species (Rideout et al. 2005, Jørgensen et al. 2006), given that the adaptive advantage is diminished. Similarly, adaptive skipping is thought to become less prevalent with age within a given species. Haddock has a maximum life span of approximately 20 yr, i.e. $\sim 5$ yr shorter than cod (Cohen et al. 1990). We might therefore anticipate less adaptive skipping in haddock than in cod (see Folkvord et al. 2014), and the age window where haddock accrue an adaptive advantage by spawning omission should theoretically also be shorter than that of cod. In view of the comparatively large numbers of old NEA haddock skipping spawning compared to NEA cod, it may be that skipping in female haddock is relatively more related to energy or stress.

Our estimated annual frequencies of skipped spawning (Fig. 4) match or even surpass those of the NEA cod (Skjæraasen et al. 2012). However, while our estimations unequivocally demonstrate frequent skipped spawning in NEA haddock, the primary purpose of this study, the absolute values, should be treated with caution. First, there is uncertainty in our estimates (Fig. 3, Table 3). Second, we have effectively assumed that our size-dependent proportions of (1) fish maturing and (2) skippers among the nondeveloping females obtained from a subset of the trawl stations can be extrapolated to the whole data set. Third, spawning NEA haddock found outside the Barents Sea at the time of sampling are not sufficiently covered by research vessels, although we did attempt a tentative correction for this (Fig. 6B). This correction arguably produced a more realistic biological pattern in the numbers of fish spawning and skipping in successive years (Fig. 5), while still indicating substantial amounts of skipping at the population level.

Metrics for being able to predict recruitment have been sought after for a long time, with SSB or egg production often used in a stock-to-recruitment relationship. In haddock populations, recruitment has been known to vary considerably even for very similar levels of stock biomass (Beverton \& Holt 1957), and haddock had consistently higher recruitment variability than cod in the same areas (Fogarty et al. 2001). Friedland et al. (2008) suggested that feeding conditions in the autumn could significantly influence mature females such that high productivity resulted in extremely strong year classes. Whether this is a causal effect or a quirk of the statistical ana- 
lyses has been questioned (Payne et al. 2009). However, the concept of 'maternal provisioning' has been put forward again by Leaf \& Friedland (2014). Lough \& O'Brien (2012) suggest a more traditional influence on year class strength, namely survival through the early life history stages. Various researchers working with reproductive biology have suggested that interannual variability in fecundity could affect year class strength through total egg production (TEP) varying considerably more than the interannual variation in SSB. As such, there is a suggestion that SSB should be replaced with TEP or stock reproductive potential (Trippel 1999, Marshall et al. 2003). While there is often a slightly better predictive relationship for recruitment by using TEP rather than SSB, the orders of magnitude of variations typically seen in recruitment are not adequately reflected in the TEPs. In the case of NEA haddock, though, a combination of variable fecundities along with fairly major incidences of skipped spawning (as shown here) could have a significant effect on the annual TEPs and thus have a major impact on year class strength. This needs to be thoroughly investigated with a longer time series of data.

In conclusion, while previously principally undocumented for haddock, skipped spawning appears to be an integral life history strategy for NEA haddock and will likely, in some years, profoundly reduce population egg production compared to that of a 'non-skipping' population. Taken together with the recently observed skipping in NEA Gadus morhua, we postulate that costs associated with their long spawning migrations make skipped spawning a common occurrence important in population regulation for these gadoids.

Acknowledgements. We thank the crews of the various IMR research vessels for collecting samples for the present study and Bente Njøs-Strand for aiding in the laboratory. The study was funded by the Norwegian Research Council (project nos. 190228 and 200497).

\section{LITERATURE CITED}

Bancroft JD, Stevens A (eds) (1996) Theory and practice of histological techniques. Churchill Livingstone, New York, NY

Bergstad OA, Jørgensen T, Dragesund O (1987) Life-history and ecology of the gadoid resources of the Barents Sea. Fish Res 5:119-161

Beverton RJH, Holt SJ (1957) On the dynamics of exploited fish populations. HMSO, London

Bull JJ, Shine R (1979) Iteroparous animals that skip opportunities for reproduction. Am Nat 114:296-303
Cohen DM, Inada T, Iwamoto T, Scialabba N (1990) FAO species catalogue, Vol 10. Gadiform fishes of the world (order Gadiformes): an annotated and illustrated catalogue of cods, hakes, grenadiers and other gadiform fishes known to date. FAO Fish Synop, FAO, Rome

Davidson AC, Hinkley DV (1997) Bootstrap methods and their application. Cambridge University Press, Cambridge

Dutil JD, Lambert Y (2000) Natural mortality from poor condition in Atlantic cod (Gadus morhua). Can J Fish Aquat Sci 57:826-836

Fogarty MJ, Myers RA, Bowen KG (2001) Recruitment of cod and haddock in the North Atlantic: a comparative analysis. ICES J Mar Sci 58:952-961

Folkvord A, Jørgensen C, Korsbrekke K, Nash RDM, Nilsen T, Skjæraasen JE (2014) Trade-offs between growth and reproduction in wild Atlantic cod. Can J Fish Aquat Sci 71:1106-1112

Friedland KD, Hare JA, Wood GB, Col LA and others (2008) Does the fall phytoplankton bloom control recruitment of Georges Bank haddock, Melanogrammus aeglefinus, through parental condition? Can J Fish Aquat Sci 65: 1076-1086

> Hedenström A (2003) Scaling migration speed in animals that run, swim and fly. J Zool 259:155-160

> Hedenström A (2008) Adaptations to migration in birds: behavioural strategies, morphology and scaling effects. Philos Trans R Soc Lond B Biol Sci 363:287-299

> Heino M, Dieckmann U, Godo OR (2002) Measuring probabilistic reaction norms for age and size at maturation. Evolution 56:669-678

Hislop JRG, Robb AP, Gauld JA (1978) Observations on effects of feeding level on growth and reproduction in haddock, Melanogrammus aeglefinus (L) in captivity. J Fish Biol 13:85-98

> Horvitz DG, Thompson DJ (1952) A generalization of sampling without replacement from a finite universe. J Am Stat Assoc 47:663-685

ICES (2012) Report of the Arctic Fisheries Working Group 2012 (AFWG). ICES CM 2012/ACOM:05. ICES, Copenhagen

Jager HI, Rose KA, Vila-Gispert A (2008) Life history correlates and extinction risk of capital-breeding fishes. Hydrobiologia 602:15-25

Jørgensen C, Ernande B, Fiksen O, Dieckmann U (2006) The logic of skipped spawning in fish. Can J Fish Aquat Sci 63:200-211

Jørgensen C, Dunlop ES, Opdal AF, Fiksen O (2008) The evolution of spawning migrations: state dependence and fishing-induced changes. Ecology 89:3436-3448

> Kjesbu OS, Righton D, Kruger-Johnsen M, Thorsen A, Michalsen K, Fonn M, Witthames PR (2010) Thermal dynamics of ovarian maturation in Atlantic cod (Gadus morhua). Can J Fish Aquat Sci 67:605-625

Lambert Y, Dutil JD (1997) Can simple condition indices be used to monitor and quantify seasonal changes in the energy reserves of Atlantic cod (Gadus morhua)? Can J Fish Aquat Sci 54:104-112

> Leaf RT, Friedland KD (2014) Autumn bloom phenology and magnitude influence haddock recruitment on Georges Bank. ICES J Mar Sci 71:2017-2025

Lough RG, O'Brien L (2012) Life-stage recruitment models for Atlantic cod (Gadus morhua) and haddock (Melanogrammus aeglefinus) on Georges Bank. Fish Bull 110: $123-140$

Lowerre-Barbieri SK, Brown-Peterson NJ, Murua $H$, 
Tomkiewicz J, Wyanski DM, Saborido-Rey F (2011) Emerging issues and methodological advances in fisheries reproductive biology. Mar Coast Fish 3:32-51

Marshall CT, Yaragina NA, Lambert Y, Kjesbu OS (1999) Total lipid energy as a proxy for total egg production by fish stocks. Nature 402:288-290

Marshall CT, O'Brien L, Tomkiewicz J, Marteinsdottir G and others (2003) Developing alternative indices of reproductive potential for use in fisheries management: case studies for stocks spanning an information gradient. J Northwest Atl Fish Sci 33:161-190

- McBride RS, Somarakis S, Fitzhugh GR, Albert A and others (2015) Energy acquisition and allocation to egg production in relation to fish reproductive strategies. Fish Fish 16:23-57

McNamara JM, Houston AI (2008) Optimal annual routines: behaviour in the context of physiology and ecology. Philos Trans R Soc Lond B Biol Sci 363:301-319

Mehault S, Dominguez-Petit R, Cervino S, Saborido-Rey F (2010) Variability in total egg production and implications for management of the southern stock of European hake. Fish Res 104:111-122

> Morbey YE, Shuter BJ (2013) Intermittent breeding in the absence of a large cost of reproduction: evidence for a non-migratory, iteroparous salmonid. Ecosphere 4:150

Mylonas CC, Bridges C, Gordin H, Rios AB and others (2007) Preparation and administration of gonadotropinreleasing hormone agonist (GnRHa) implants for the artificial control of reproductive maturation in captivereared Atlantic bluefin tuna (Thunnus thynnus thynnus). Rev Fish Sci 15:183-210

Nahrgang J, Varpe O, Korshunova E, Murzina S, Hallanger IG, Vieweg I, Berge J (2014) Gender specific reproductive strategies of an Arctic key species (Boreogadus saida) and implications of climate change. PLoS ONE 9:e98452

> Payne MR, Dickey-Collas M, Nash RDM (2009) Comment on 'Does the fall phytoplankton bloom control recruitment of Georges Bank haddock, Melanogrammus aeglefinus, through parental condition?' Can J Fish Aquat Sci 66:869-872

Ricker WE (1954) Stock and recruitment. J Fish Res Board Can 11:559-623

Ricklefs RE, Wikelski M (2002) The physiology/life-history nexus. Trends Ecol Evol 17:462-468

Rideout RM, Tomkiewicz J (2011) Skipped spawning in fishes: more common than you might think. Mar Coast Fish 3:176-189

Rideout RM, Burton MPM, Rose GA (2000) Observations on mass atresia and skipped spawning in northern Atlantic Cod, from Smith Sound, Newfoundland. J Fish Biol 57: 1429-1440

Rideout RM, Rose GA, Burton MPM (2005) Skipped spawning in female iteroparous fishes. Fish Fish 6:50-72

Rideout RM, Morgan MJ, Lilly GR (2006) Variation in the frequency of skipped spawning in Atlantic cod (Gadus morhua) off Newfoundland and Labrador. ICES J Mar Sci 63:1101-1110

Editorial responsibility: Stylianos Somarakis, Heraklion, Greece
Saborido-Rey F, Junquera S (1998) Histological assessment of variations in sexual maturity of cod (Gadus morhua L.) at the Flemish Cap (north-west Atlantic). ICES J Mar Sci 55:515-521

> Sitar SP, Jasonowicz AJ, Murphy CA, Goetz FW (2014) Estimates of skipped spawning in lean and siscowet lake trout in southern Lake Superior: implications for stock assessment. Trans Am Fish Soc 143:660-672

Skjæraasen JE, Kennedy J, Thorsen A, Fonn M, Strand BN, Mayer I, Kjesbu OS (2009) Mechanisms regulating oocyte recruitment and skipped spawning in Northeast Arctic cod (Gadus morhua). Can J Fish Aquat Sci 66: 1582-1596

Skjæraasen JE, Nash RDM, Kennedy J, Thorsen A, Nilsen T, Kjesbu OS (2010) Liver energy, atresia and oocyte stage influence fecundity regulation in Northeast Arctic cod. Mar Ecol Prog Ser 404:173-183

> Skjæraasen JE, Nash RDM, Korsbrekke K, Fonn M and others (2012) Frequent skipped spawning in the world's largest cod population. Proc Natl Acad Sci USA 109: 8995-8999

- Skjæraasen JE, Korsbrekke K, Kjesbu OS, Fonn M, Nilsen T, Nash RDM (2013) Size-, energy- and stage-dependent fecundity and the occurrence of atresia in the Northeast Arctic haddock Melanogrammus aeglefinus. Fish Res 138:120-127

> Thorsen A, Kjesbu OS (2001) A rapid method for estimation of oocyte size and potential fecundity in Atlantic cod using a computer-aided particle analysis system. J Sea Res 46:295-308

> Trippel EA (1999) Estimation of stock reproductive potential: history and challenges for Canadian Atlantic gadoid stock assessments. J Northwest Atl Fish Sci 25:61-81

Trotter AA, Blewett DA, Taylor RG, Stevens PW (2012) Migrations of common snook from a tidal river with implications for skipped spawning. Trans Am Fish Soc 141:1016-1025

> Tyler CR, Sumpter JP (1996) Oocyte growth and development in teleosts. Rev Fish Biol Fish 6:287-318

$>$ Ulltang $\varnothing$ (1996) Stock assessment and biological knowledge: Can prediction uncertainty be reduced? ICES J Mar Sci 53:659-675

Venables WN, Ripley BD (1999) Modern applied statistics with S-PLUS. Springer, New York, NY

> Weber TP, Ens BJ, Houston AI (1998) Optimal avian migration: a dynamic model of fuel stores and site use. Evol Ecol 12:377-401

Witthames PR, Thorsen A, Murua H, Saborido-Rey F and others (2009) Advances in methods for determining fecundity: application of the new methods to some marine fishes. Fish Bull 107:148-164

Witthames PR, Thorsen A, Kjesbu OS (2010) The fate of vitellogenic follicles in experimentally monitored Atlantic cod Gadus morhua (L.): application to stock assessment. Fish Res 104:27-37

> Zera AJ, Harshman LG (2001) The physiology of life history trade-offs in animals. Annu Rev Ecol Syst 32:95-126

Submitted: August 14, 2014; Accepted: January 27, 2015

Proofs received from author(s): March 30, 2015 